\title{
What is Masters Level Education in Informatics?
}

\author{
Michael Caspersen \\ University of Aarhus, Denmark \\ mec@daimi.au.dk \\ Arnold Pears, \\ Uppsala University, Sweden \\ Arnold.Pears@it.uu.se
}

\author{
Lillian (Boots) Cassell, \\ Villanova University, USA \\ cassell@acm.org \\ Stephen Seidman, \\ University of Central \\ Arkansas, USA \\ sseidman@uca.edu
}

\author{
Gordon Davies \\ ACM Education Board, UK \\ gordon.davies7@virgin.net \\ Heikki Topi \\ Bentley College, USA \\ topi@bentley.edu
}

\begin{abstract}
Adoption of the Bologna Accord in the European Higher Education Area (EHEA) represents a concerted move towards harmonisation of educational outcomes in higher education at the Bachelor, Masters and PhD levels.

At a time when European systems are undergoing significant examination and modification, this project addresses the need for greater understanding of the nature of Masters level education in the Informatics disciplines across Europe and the United States. The poster presents the current findings of the project, and is intended to prompt discussion about the content and expected outcomes of such programmes world-wide.
\end{abstract}

\section{Categories and Subject Descriptors}

K.3.2 [Computers and Education]: Computer and Information Science Education

\section{General Terms}

THEORY

\section{Keywords}

Informatics education, Curricula, Inventory, Comparability

\section{CONTEXT}

The current state of flux in the EHEA surrounding the harmonisation of educational programmes in response to the Bologna Declaration [1] makes a review of the role Masters Educational in Informatics highly pertinent.

This project will,

Document Masters level programs in Informatics.

Categorize existing/emerging programs and program goals.

Identify programs and curriculum recommendations that can serve as exemplars.

Document widely accepted expectations of Master's level programs in informatics and provide benchmarks against which an individual program can measure itself.

Copyright is held by the author/owner(s).

ITiCSE'08, June 30-July 2, 2008, Madrid, Spain.

ACM 978-1-60558-115-6/08/06.

\section{METHOD AND ACTIVITIES}

Compiling and analysing data related to Informatics Education Programmes in the EHEA and USA is conducted by an international panel of experts composed of representatives from the two major international professional organisations relevant for Informatics professionals, the IEEE and ACM (see the author list of the poster for details). The panel will meet twice during the project to work on the data and to set priorities for futher evaluation efforts. The first of these meetings was held in February 2008 at Bentley College, USA. The second meeting is tentatively scheduled for June 2008 and will be hosted by Uppsala University, Sweden.

Data for the project is solicited from partner organizations based in Europe and the United States. ASIIN, a German accreditation agency, can contribute experiences with the accreditation of Masters programs in Informatics in Germany and with organising the Euro-Inf project. The BCS is the UK professional body for informatics and contributes experience with developing learning outcomes and accreditation for Masters degrees, as well as providing a link to Euro-Inf. The two US organizations ACM and IEEE-CS are both professional bodies for informatics and contribute their experiences with curriculum standards, outcomes-based education and accreditation of undergraduate programmes.

\section{DELIVERABLES}

The project report provides a classification system and explains how it can be used to organize various degrees and qualifications. This will enhance the transparency of educational structures and programs by associating groups of learning outcomes and competencies with various types of degrees. Credit systems and program length differences between the U.S. and Europe will be illustrated and relationships clarified. Attention will be focused on current and pending reforms in higher education in Europe and the U.S. The resulting classification system will provide a basis for quality assurance and accreditation standards where those are emerging and where there is acceptance of these tools.

\section{REFERENCES}

[1] The Bologna Declaration of 19 June 1999. Technical report, European Ministers of Education, Bologna, Italy, 1999. Accessible at http://www.bologna-bergen2005.no/Docs/00Main_doc/990719BOLOGNA_DECLARATION.PDF. Accessed on August 4, 2006. 